\title{
A morphometric study of microvascular pathology following experimental rupture of Reissner's membrane
}

\author{
Lynn Carlisle Shaddock ${ }^{1}$, Charles G. Wright ${ }^{2}$ and Roger P. Hamernik ${ }^{3}$ \\ Kresge Hearing Research Institute, University of Michigan, 301 East Ann Sireet, Ann Arbor, MI 48109 . \\ 2 Department of Otolaryngology, University of Texas Health Science Center at Dallas, 5323 Harry Hines Boulevard, Dallas, TX 75235, \\ and ${ }^{3}$ Callier Center for Communication Disorders, University of Texas at Dallas, 1966 Inwood Raad, Dallas, TX 75235, U.S.A.
}

(Received 19 June 1985; accepted 20 August 1985)

\begin{abstract}
In a previous paper (this volume) we described a method for evaluating the cochlear microvasculature. This method was applied to the analysis of lateral wall tissue from chinchillas sacrificed $1 \mathrm{~h}, 24 \mathrm{~h}, 1$ week and 3 weeks after surgical rupture of Reissner's membrane. The degree, direction, and time course of pathological changes seen in the microvessels were different for the system of stria vascularis vessels, the system of spiral ligament vessels, and the system of spiral prominence vessels. These results indicate that it is important to evaluate all of the lateral wall vessels rather than just the stria vascularis, and emphasize the importance of dividing the microvasculature into three independent systems, in order to obtain a clearer perspective on microvascular changes which occur following cochlear trauma.
\end{abstract}

morphometrics, cochlear microvasculature, Reissner`s membrane, stria vascularis, spiral ligament, spiral prominence

\section{Introduction}

Reissner's membrane, also known as the vestibular membrane, serves the vital function of preventing perilymph in scala vestibuli from mixing with endolymph in scala media. Mixing of these cochlcar fluids is thought to cause degeneration of sensory cells and strial atrophy and thus compromise the physiological integrity of the cochlea (Duvall, 1968; Duvall and Hukee, 1981; Lawrence, 1966; Lawrence and McCabe, 1959). Surgical rupture of Reissner's membrane has been used as a technique to study the circulation of endolymph (Duvall. 1968; Duvall and Hukee, 1981; Lawrence, 1966; Lawrence and McCabe, 1959) and the effect of the intermixing of endolymph and perilymph on various structures in the cochlea (Duvall, 1968; Duvall and Hukee, 1981). Rupture of Reissner's membrane has been implicated in several types of cochlear pathology. It has been suggested (Lawrence and McCabe, 1959; Schuknecht et al., 1962) that rupture of Reissner's membrane and mixing of perilymph and endolymph are responsible for the tinnitus and fluctuating deafness asso- ciated with Ménière's disease. Kimura (1962) reported tears in Reissner's membrane in guinea pigs with experimentally-induced endolymphatic hydrops. Rupture of Reissner's membrane also often occurs as a result of exposure to high intensity noise (Eldredge et al, 1957; Lawrence and Yantis. 1957; Spoendlin, 1976; Voldrich, 1972).

Surgical rupture of Reissner's membrane was chosen as a means for creating vascular pathology in this experiment because it results in a well defined lesion to the cochlear lateral wall. Whether Reissner's membrane is ruptured experimentally or due to endolymphatic hydrops or noise exposure, the resultant pathology is similar. The predominant finding is a localized lesion affecting both the organ of Corti and the stria vascularis (Kimura, 1962; Lawrence, 1966; Lawrence and Yantis, 1957; Schuknecht, 1981; Spoendlin, 1976: Voldrich, 1972), although a number of studies have also reported apical spread of degeneration in both structures (Eldredge et al., 1957; Lawrence and Yantis, 1957; Spoendlin, 1976; Voldrich. 1972).

Our previous report (accompanying paper: 
Shaddock et al., 1985) showed that the vessels of the cochlear lateral wall can be classified into three systems based on their morphology and on the structures they supply. The purpose of this study was to see if these three vessel systems responded differently to cochlear trauma.

\section{Materials and Methods}

Chinchillas were used as experimental subjects; animals ranged in age from 8 months to 8 years and were all of the same coat color. Young animals and older animals were included in each group, and the mean age per group ranged from 13 months to 35 months. A total of 50 cochleas were needed for the study: 10 at each of four postsurgery survival times, five sham operated controls and five unoperated controls. A sufficient number

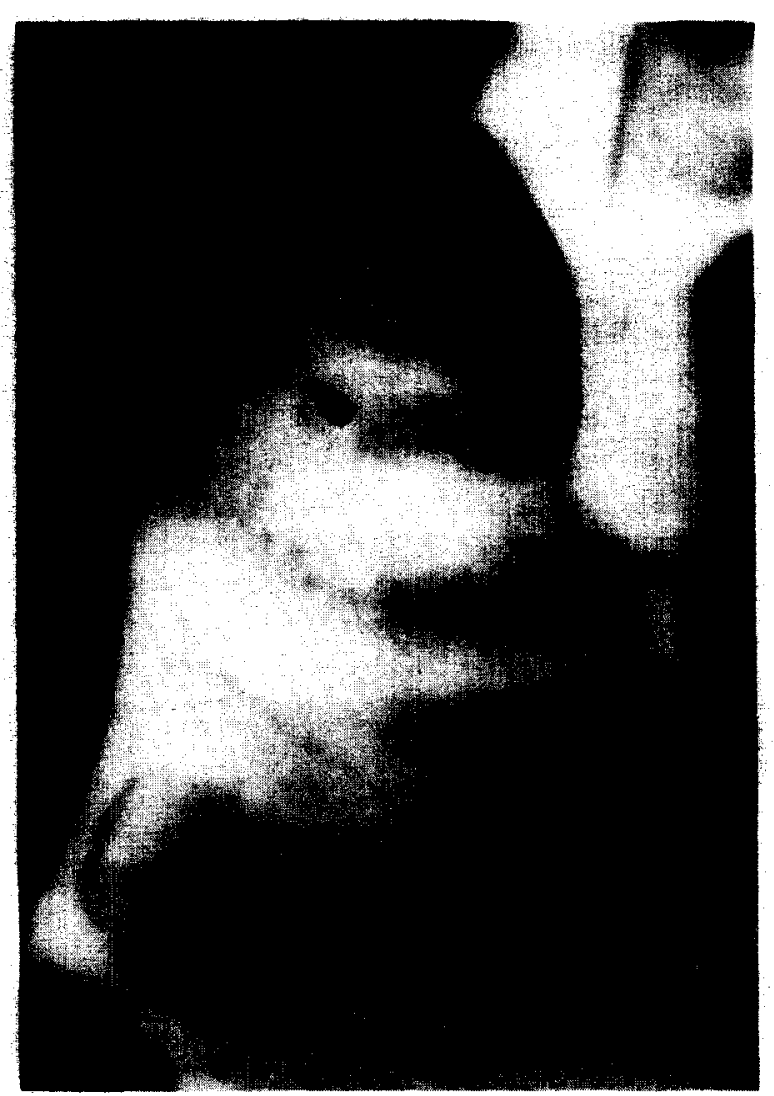

Fig. 1. Location of the hole drilled in the otic capsule. A stainless-steel microneedle was inserted through this hole and gently rotated to rupture Reissner's membrane. of animals was used to yield 10 cochleas in which the surgical procedure was successful for each survival time. The sham operated control group consisted of five cochleas in which the surgical procedure was performed but Reissner's membrane was not ruptured. The unoperated control group consisted of the five normal cochleas included in our previous study.

Each animal was anesthetized by subcutaneous injection of $0.15 \mathrm{ml} \mathrm{Ketamine}(100 \mathrm{mg} / \mathrm{ml})$ with acepromazine $(10 \mathrm{mg} / \mathrm{ml})$ and xylazine $(20 \mathrm{mg} / \mathrm{ml})$ in a 3:1:3 mixture. The bulla was exposed and opened through the submandibular triangle so that the apical and middle turns of the cochlea were easily visualized. A dental pick was used to drill manually a hole through the otic capsule into scala vestibuli of the middle cochlear turn at a distance approximately $50 \%$ from the cochlear apex. A stainless-steel microneedle with a $30^{\circ}$ bend at the tip was inserted through the hole and rotated in order to rupture Reissner's membrane. Fig. 1 illustrates the size and location of the hole in the otic capsule. The hole was covered with Gelfoam; the incision was sutured and the procedure was repeated on the other ear.

Animals were killed at $1 \mathrm{~h}, 24 \mathrm{~h}, 1$ week and 3 weeks after surgery. All animals were killed while anesthetized; animals in the $1 \mathrm{~h}$ survival group were still asleep and required no further anesthetic. Animals in the other post-surgery survival groups were anesthetized and allowed to sleep for $1 \frac{1}{2}$ hours before decapitation; therefore all animals were anesthetized for approximately the same period of time when killed.

The protocol for tissue preparation is reported elsewhere (this issue). After exposure of scala media in the area corresponding to the location of the hole in the otic capsule, Reissner's membrane was carefully examined to determine if it had been successfully ruptured. A $3 \mathrm{~mm}$ portion of the lateral wall centered about the location of the rupture was then removed. This tissue specimen was rehydrated and bleached in 3\% hydrogen peroxide for $5 \mathrm{~min}$ to remove excess osmium so that the vessels could be more easily visualized. It was then mounted on a glass slide in glycerol for morphometric analysis.

The morphometric technique described in our preceding paper (this issue) was used to collect 

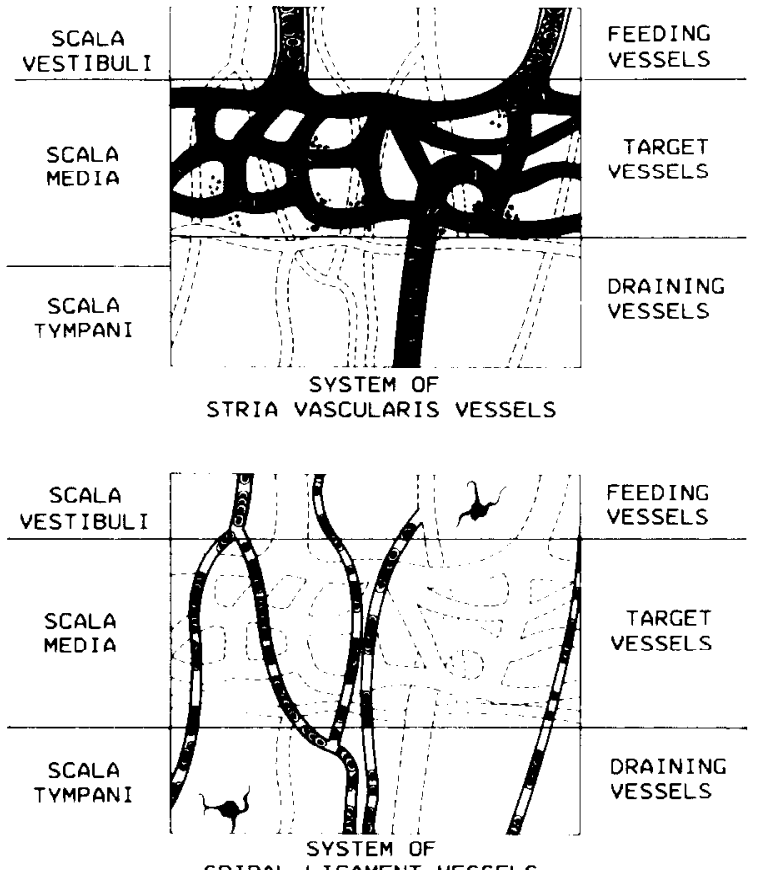

SPIRAL LIGAMENT VESSELS

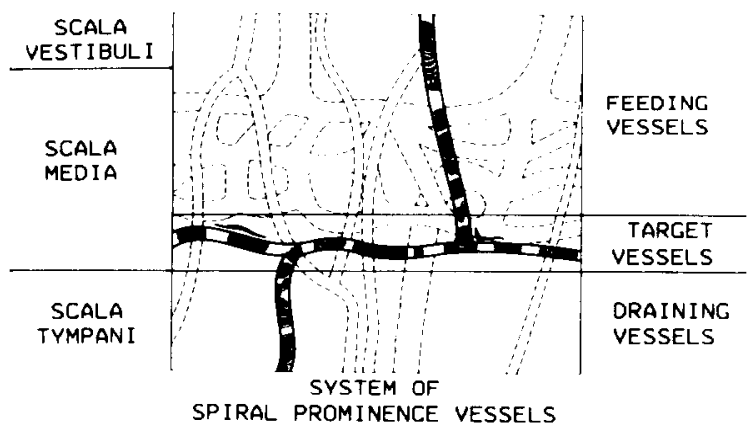

Fig. 2. Schematic representations of the three vessel systems as described in the text. Each vessel system has been divided into three subsystems designated as feeding vessels, target vessels and draining vessels for data collection and analysis.

and analyze the data. The material was coded so that the investigators did not know the experimental group from which each specimen came. The data were sorted for the statistical analysis by survival time and also by vessel system and location. The term vessel system refers to the three systems previously defined for the lateral wall vasculature on the basis of vessel morphology and the structures which the vessels supply. The vessels comprising the three systems are those of the stria vascularis, of the spiral ligament, and of the spiral prominence (Fig. 2). Each vessel system was subdivided into three segments (i.e., feeding vessels, target vessels, and draining vessels) which corresponded to locations in the lateral wall.

\section{Results}

Statistical analyses were performed for the variables vascular density, RBC density, vessel width. aggregation density and pigment density. The unoperated control group and the sham operated control group were compared in a two-way ANOVA in which the factors were group identity (sham-operated and unoperated) and location (feeding vessels, target vessels, draining vessels). The results showed a significant increase in the sham-operated control group for aggregation density $\left(F_{1.54}=16.34, P<0.01\right)$ and pigment density ( $\left.F_{1,54}=17.09, P<0.01\right)$; therefore the two control groups were not combined for the remaining statistical tests. These results indicate that the mechanical trauma caused by drilling the hole in the otic capsule did cause some changes in the lateral wall.

To see if the three vessel systems were significantly different over time, a two-way ANOVA was

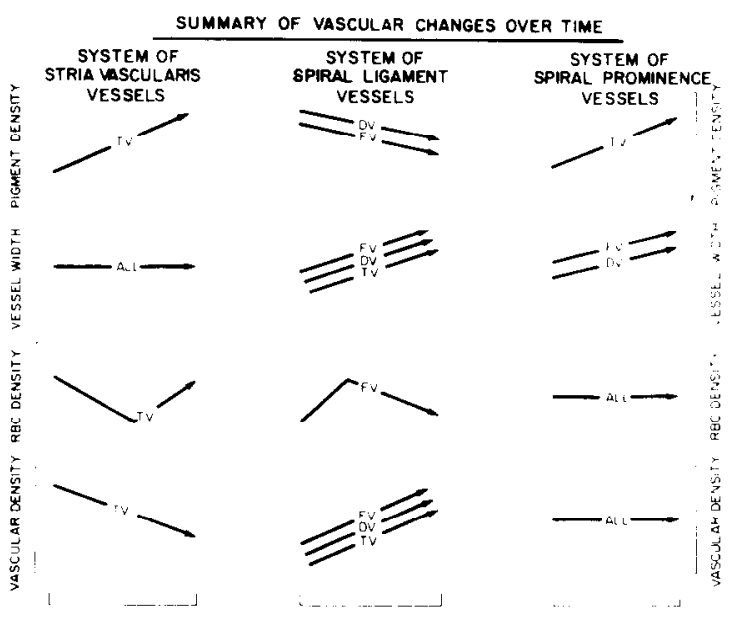

Fig. 3. Summary of vascular changes over time for all cases in which significant $(P<0.05)$ differences were found with the ANOVA procedure. Arrows indicate whether the mean value for each variable increased, decreased or remained unchanged over time. FV, feeding vessels; TV, target vessels; DV, draining vessels (as identified in Fig. 2). 
TABLE I

RESULTS OF SYSTEM $\times$ SURVIVAL TIME TWO-WAY ANOVA

\begin{tabular}{|c|c|c|c|c|c|}
\hline & $\begin{array}{l}\text { Vascular } \\
\text { density }\end{array}$ & $\begin{array}{l}\text { RBC } \\
\text { density }\end{array}$ & $\begin{array}{l}\text { Vessel } \\
\text { width }\end{array}$ & $\begin{array}{l}\text { Aggregation } \\
\text { density }\end{array}$ & $\begin{array}{l}\text { Pigment } \\
\text { density }\end{array}$ \\
\hline \multicolumn{6}{|c|}{ A. Main effect of vessel system $(P<0.001)$} \\
\hline \multicolumn{6}{|c|}{ Feeding } \\
\hline vessels & $x$ & $x$ & $x$ & - & CNT \\
\hline \multicolumn{6}{|l|}{ Target } \\
\hline vessels & $x$ & $x$ & $x$ & $\cdots$ & $x$ \\
\hline \multicolumn{6}{|l|}{ Draining } \\
\hline vessels & $x$ & $x$ & $x$ & - & CNT \\
\hline \multicolumn{6}{|c|}{ B. Main effect of survival time $(P<0.01)$} \\
\hline \multicolumn{6}{|l|}{ Feeding } \\
\hline vessels & - & $x$ & - & $x$ & - \\
\hline \multicolumn{6}{|l|}{ Target } \\
\hline vessels & $x$ & $x$ & $x$ & - & $x$ \\
\hline \multicolumn{6}{|l|}{ Draining } \\
\hline vessels & - & - & $x$ & - & - \\
\hline \multicolumn{6}{|c|}{ C. Interaction effect; system $\times$ survival $(P<0.05)$} \\
\hline \multicolumn{6}{|c|}{ Feeding } \\
\hline vessels & - & - & $-m$ & - & - \\
\hline \multicolumn{6}{|l|}{ Target } \\
\hline vessels & $x$ & $x$ & $x$ & - & $x$ \\
\hline \multicolumn{6}{|l|}{ Draining } \\
\hline vessels & - & - & - & - & - \\
\hline
\end{tabular}

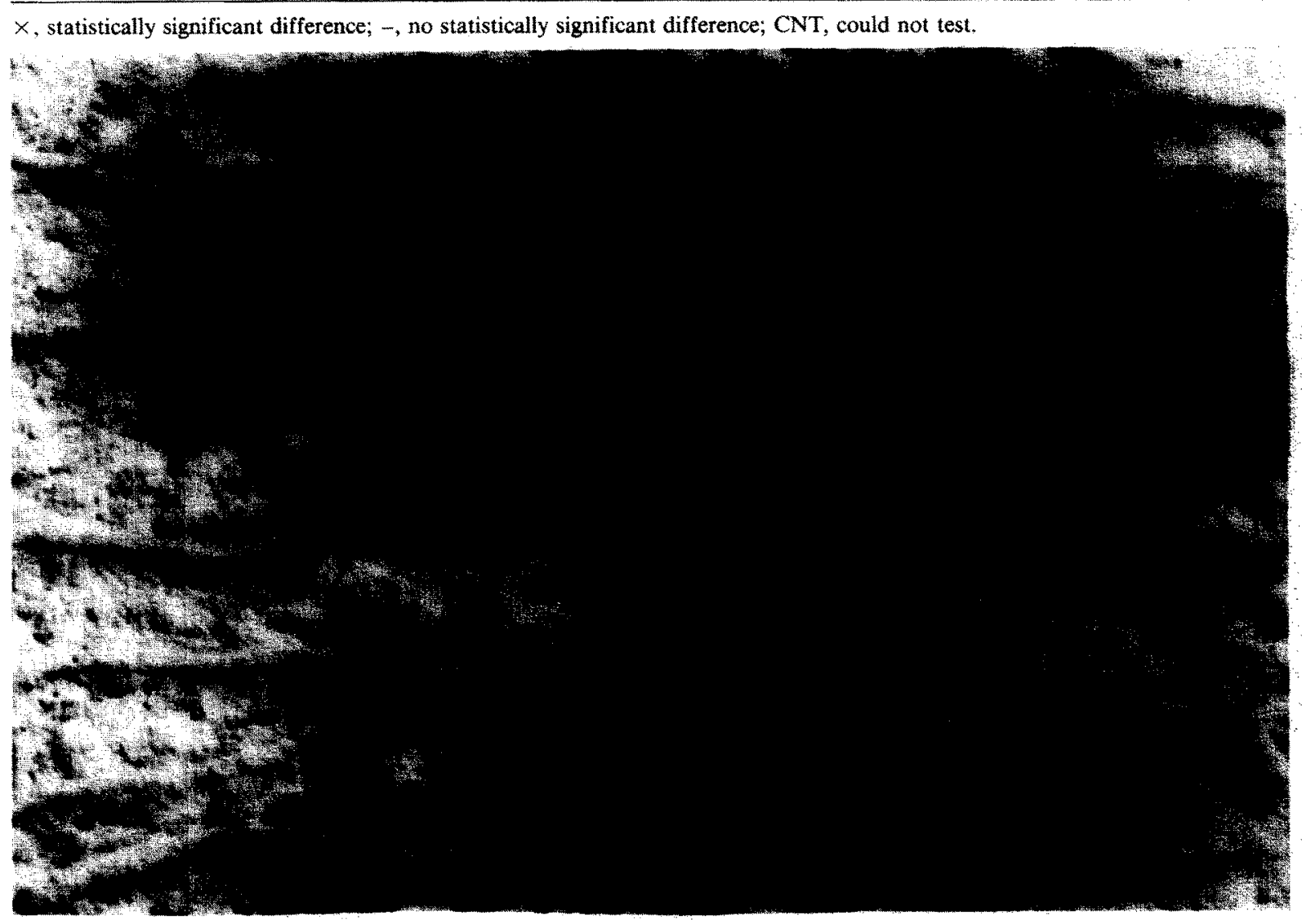

Fig. 4. Stria vascularis from an animal in the unoperated control group. Vessel width is fairly uniform for all vessels of the stria vascularis, and the capillaries are so well packed with RBCs that the vessels are completely opaque and individual RBC profiles cannot be resolved. 
performed in which the factors were system and survival time (the two control groups were included). The test was performed three times: for data collected on feeding vessels, target vessels, and draining vessels. The results are contained in Table I. which lists the main effects for vessel system and survival time and the interaction effects for each variable.

There were highly significant differences $(P<$ 0.001 ) between the three vessel systems (Table I, A) for vascular density, RBC density and vessel width at all locations and for pigment density in the target vessels. Significant $(P<0.01)$ effects of survival time (Table I, B) were found for all variables except aggregation density in the target vessels, for RBC density and aggregation density in the feeding vessels, and for vessel width in the draining vessels. Significant $(P<0.05)$ interactions between vessel system and survival time were found for all variables except aggregation density in the target vessels; no interaction effects were seen for feeding or draining vessels.

In all cases in which significant $(P<0.05)$ differences over time were found, the Scheffe multiple contrasts test (Zar, 1980) was used to test for significant $(P<0.05)$ trends in the data. The results of these Scheffe tests are shown in Fig. 3, which summarizes the relationship over time between vessel systems, locations, and dependent variables. Several conclusions can be drawn based on Fig. 3:

When significant changes occurred in the system of stria vascularis vessels, they occurred in the target vessels. The vessels feeding and draining the stria vascularis were unaffected by the insult.

- Changes to the system of spiral ligament vessels tended to affect all locations (i.e., feeding, target and draining vessels).

- The system of spiral prominence vessels was least affected by the insult.

- Changes in vascular density and RBC density were inversely related over time for the system of stria vascularis vessels and the system of spiral ligament vessels.

- There was a steady increase in vessel width over time for all of the system of spiral ligament vessels and for the vessels feeding and draining the spiral prominence. Vessel width was un- changed over time for the system of stria vascularis vessels and the vessel of the spiral prominence.

- Changes in pigment density were inversely related over time for the systems of strial and of spiral prominence vessels and the system of spiral ligament vessels.

Although rupture of Reissner's membrane resulted in changes in vessel morphology throughout the lateral wall, the most pronounced changes were seen in the stria vascularis. Fig. 4 shows the vascular pattern of the stria vascularis from the middle turn of a normal chinchilla cochlea. Most of the vessels were oriented in a longitudinal direction although vertical anastomoses were frequent. RBC density was so high in normal strial vessels that they appeared opaque and individual RBC profiles could not be resolved. Fig. 5 shows the stria vascularis at $1 \mathrm{~h}$ after rupture of Reissner's membrane. There was a pronounced variation in vessel width when compared to the normal stria shown in Fig. 4. The large vessel that runs along the bottom margin of the stria was dilated to twice its normal size and was engorged with RBCs. These dilated vessels were always directly connected to a vessel feeding the stria vascularis or a vessel draining the stria vascularis. While some strial vessels were dilated, others were narrowed and contained plasma gaps between clusters of RBCs, so that the net result was an average vessel width that was only slightly greater, and not significantly different, than the average vessel width of the strial vessels in the control group. Strial edema and strial atrophy were present in animals killed $24 \mathrm{~h}$ after Reissner's membrane rupture. Strial atrophy always began at the top margin of the stria, directly below the attachment of Reissner's membrane as is shown in Fig. 6. Although the large differences in vessel width seen at $1 \mathrm{~h}$ were no longer present at $24 \mathrm{~h}, \mathrm{RBC}$ density continued to decrease as evidenced by the increase in plasma gaps between clusters of RBCs. At 1 week after Reissner's membrane rupture there were no signs of strial edema but strial atrophy continued to spread downwards from the top margin of the stria. RBC density had increased to near control values but vascular density was still greatly reduced and the pattern of strial vessels was quite different than that seen in the normal stria. The 


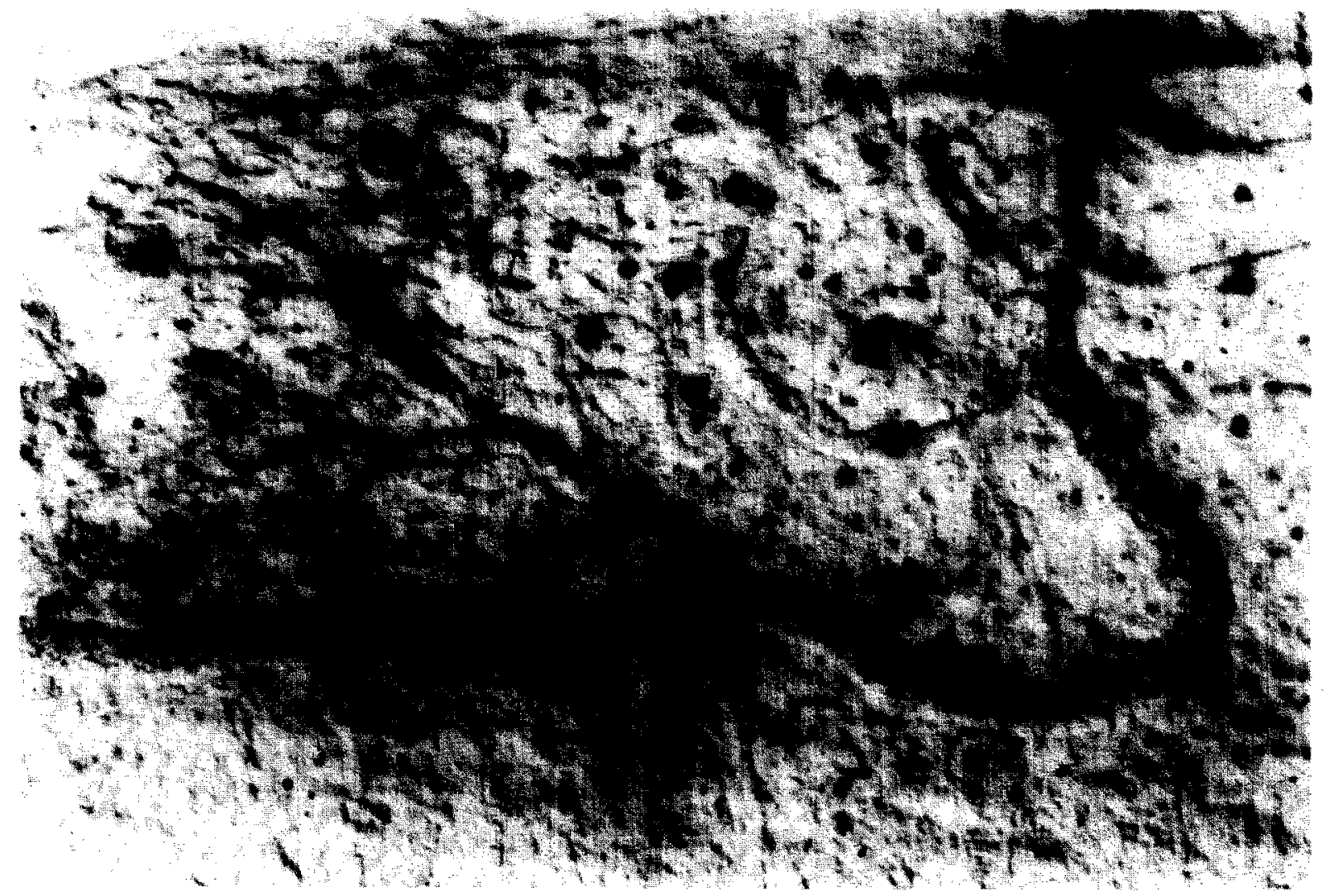

Fig. 5. Stria vascularis from an animal killed $1 \mathrm{~h}$ after rupture of Reissner's membrane. The large vessel running longitudinally at ine basal edge of the stria is dilated to twice its normal size; other vessels are narrowed and have plasma gaps between clusters of $R B C \mathrm{~s}$.

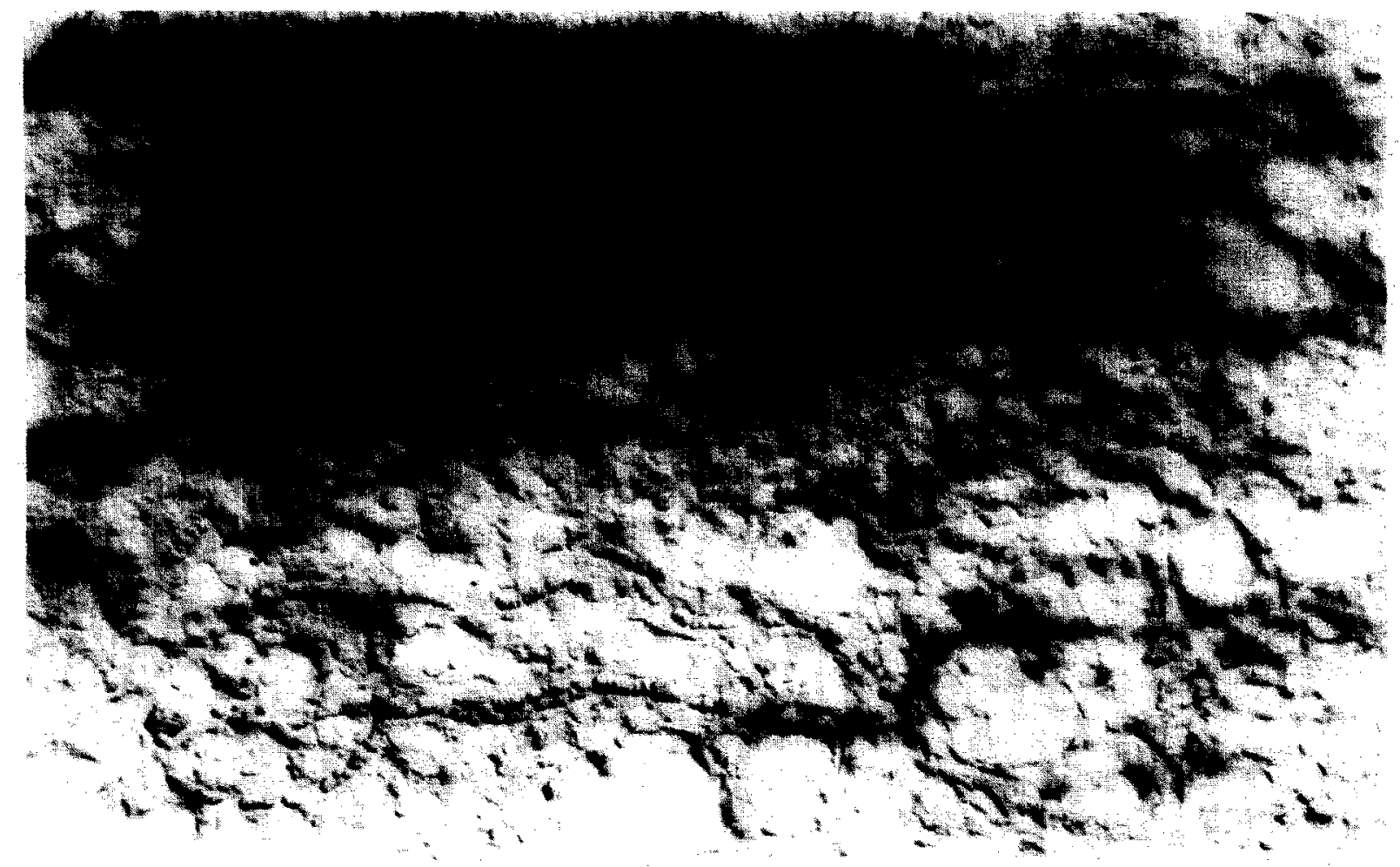

Fig. 6. Stra vascularis from an animal killed $24 \mathrm{~h}$ after rupture of Reissner's membrane. The stria appears vacuolized. due to edematous intermediate cells or to accumulation of extracellular fiuid. and RBC density is greatly reduced. 


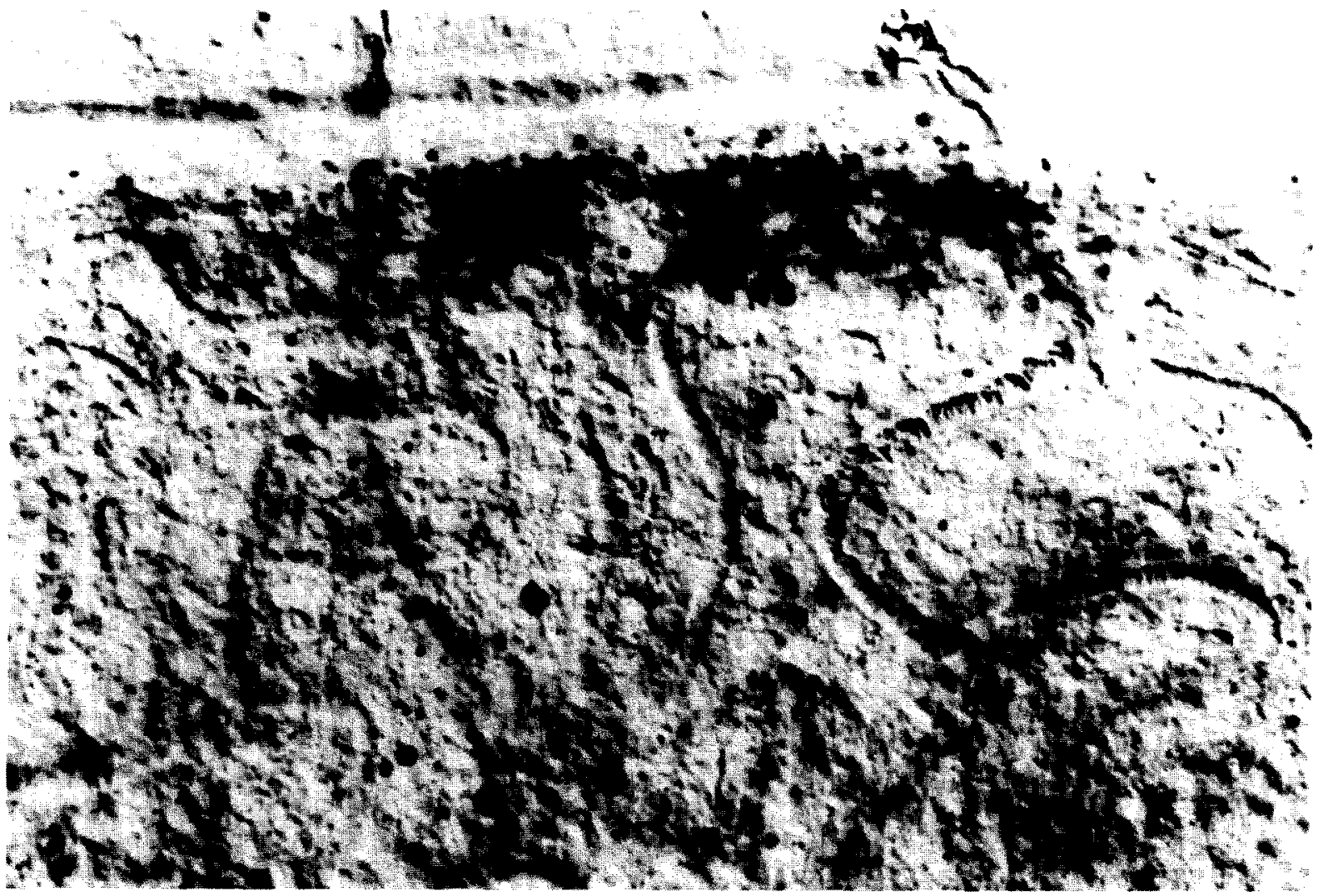

Fig. 7. Stria vascularis from an animal killed 1 week after rupture of Reissner's membrane. The vascular network is simplified due to the degeneration of some strial vessels and there is an area of dense pigmentation at the upper edge of the stria.

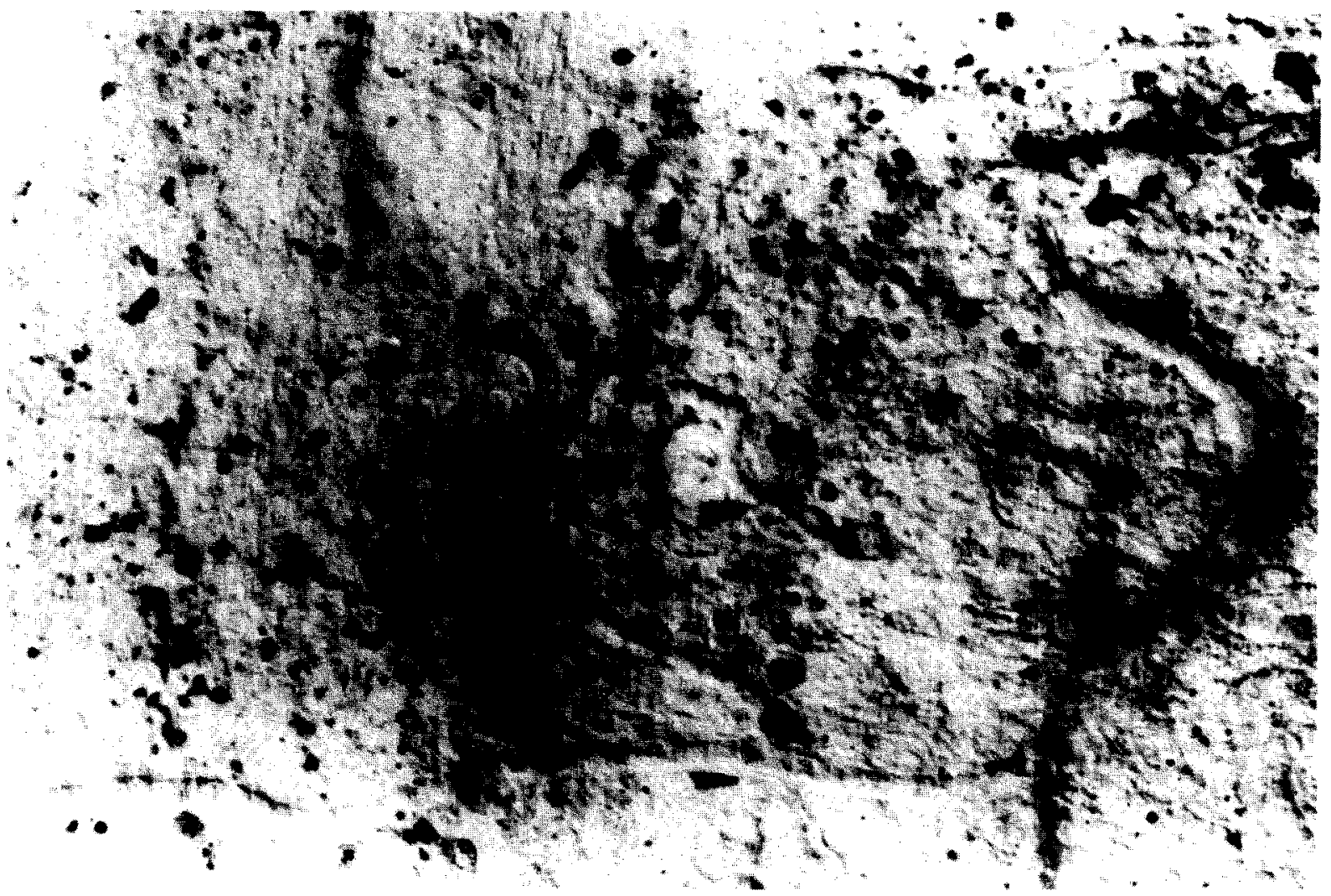

Fig. 8. Stria vascularis from an animal killed 3 weeks after Reissner's membrane rupture. The stria has completely atrophied in the area shown in the left half of the micrograph, except for a single, longitudinally-oriented vessel at the bottom margin. 


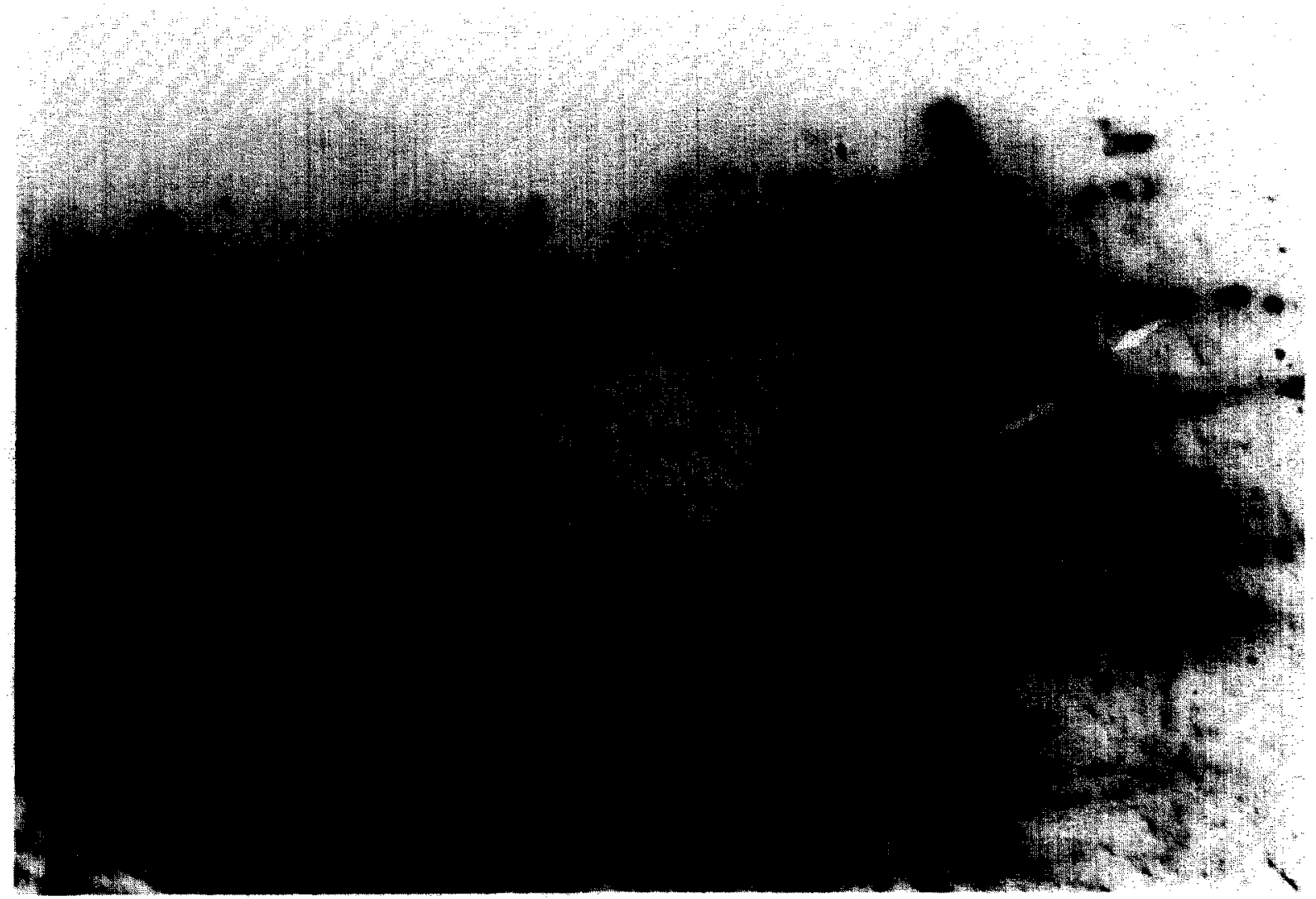

Fig. 9. Scala vestrbuli portion of the spiral higament in a specimen from the unoperated control group. The arrows indicate 'sleeved" vessels feeding into the stria.

well organized, predominantly longitudinal pattern seen in the normal stria (Fig. 4) had been replaced by an erratic series of vessel loops by 1 week after Reissner's membrane rupture (Fig. 7). In the 3 week survival group, the stria vascularis had severely atrophied in an area corresponding to the rupture of Reissner's membrane. All that remained was one strial vessel along the bottom edge (Fig. 8). The network of strial vessels reappeared in the area shown toward the right side of Fig. 8, and, although the vascular pattern was irregular, the $\mathrm{RBC}$ density had regained its normal value. The remaining vessels in this area were opaque due to the proportion of RBCs, just as in the normal stria (Fig. 4).

Pigment density in the stria vascularis was found to increase in both the sham-operated control group and in animals with Reissner's membrane ruptures. As indicated in Fig. 3, there was an increase of some $300 \%$ in strial pigmentation over the three-week period following rupture of Reissner's membrane. An increase in pigment density also occurred in the spiral prominence, although it was less pronounced than in the stria. It is of interest to note that pigment density actually decreased in the spiral ligament, in both scala tympani and scala vestibuli, over the three-week experimental period.

The pigmented substance that accumulated in the stria vascularis consisted of golden-brown, intracellular granules or masses of dark brown material. The native brown color of the pigment did not appear to darken appreciably after osmium staining and it was unchanged after exposure to $3 \%$ hydrogen peroxide for $5 \mathrm{~min}$. Specimens containing pigment were not tested for autofluorescence under ultraviolet illumination. 


\section{Discussion}

The biggest change in vascular density was the decrease that occurred in the stria vascularis. Since vascular density is defined as the proportion of the field occupied by vessels, a decrease in vascular density must mean either a decrease in the width of the vessels or a decrease in the number of vessels in the field. The average width of vessels in the stria never changed more than $0.5 \mu \mathrm{m}$ and this was certainly not enough of a change in width to account for the $45 \%$ decrease measured in vascular density. This means that the decrease in vascular density must be due to a decrease in the number of vessels in the stria. To understand how vessels could 'disappear' as quickly as $24 \mathrm{~h}$ after the injury we must examine the laws governing changes in capillary diameter. The capillary wall consists of a single layer of endothelial cells surrounded by a basement membrane (Rhodin, 1973). Pericytes are occasionally found between the endothelial cells and the basement membrane, but there is not conclusive evidence that pericytes have contractile properties (Zweifach, 1971). It has been shown that changes in the extravascular matrix can physically compress capillaries to the point of complete occlusion and that this complete occlusion can continue for extended periods of time (Zweifach, 1971). This is because capillaries act like 'tunnels in a gel' (Fung et al., 1965) which means that the surrounding medium is responsible for the patency of the capillary. It is reasonable to assume that strial edema caused an increase in extraluminal pressure on the walls of the strial capillaries. At one hour after the injury, changes in the width of individual vessels of the strial network were seen; some vessels were greatly dilated and engorged with RBCs, others were narrower than normal and had a less than normal density of RBC's. Large capillaries tend to pull RBCs from smaller capillaries by a process known as plasma skimming (Albrecht et al., 1979; Folkow and Neil, 1971). Between one hour and 24 hours post-surgery RBC density decreased by $30 \%$ in the vessels feeding the stria and by $42 \%$ in the strial vessels. These decreases resulted in an even greater tendency for RBCs to be located in the larger strial capillaries, which in turn lowered the internal resistance of the narrower strial capillaries, allowing them to be occluded by the increasing extravascular pressure. These occluded vessels eventually degenerated, leaving the simplified network of strial vessels seen at 1 and 3 weeks after surgery. At none of the post-surgery survival times evaluated in this study were avascular channels or intervascular strands (Hawkins, 1971) seen in the $1 \mathrm{~mm}$ area analyzed. The failure to find such evidence of ongoing vascular degeneration may be due to limitations in the resolution of the video image from which the measurements were made or could be related to the severity of the trauma in the immediate area of the rupture.

The vessels in the spiral ligament and the vessels feeding and draining the spiral prominence showed a steady increase in average vessel width over time. There are two possible mechanisms to explain this dilation; an overall increase in the amount of blood supplied by the arterioles in the modiolus could result in a dilation of the capillaries to compensate for the increase in intraluminal pressure caused by the increase in blood, or as a result of the trauma there could be an increase in the amount of extracellular fluid that is absorbed by the vessels, thus increasing their diameter (Cameron, 1967). It seems strange that the average width of the vessels feeding the stria never changed since all of the other vessels located in scala vestibuli increased over time. Figure 9 shows the scala vestibuli portion of the lateral wall from a chinchilla in the control group. There is a 'sleeve' of dense, homogeneous material around only the vessels feeding the stria vascularis which ends abruptly at the attachment of Reissner's membrane (Duvall and Hukee. 1981). Perhaps this 'sleeve' served to insulate the vessels feeding the stria from changes in the fluid environment by providing a relatively rigid extravascular matrix.

Aggregation density was not significantly different in the three vessel systems, but aggregation density did increase over time. especially in the scala vestibuli. In low flow states, aggregation of $\mathrm{RBCs}$ occurs due to interactions between protein macromolecules and the surface of the RBCs (Knisely et al., 1945; Wells, 1965). This 'sludging' of blood is seen in a variety of circumstances ranging from mechanical injuries to infectious diseases. It is a reversible phenomenon; as soon as flow rate increases, the aggregations break apart. 
Since aggregation density was significantly increased in the sham-operated control group, it seems that the increase must be due at least in part to the mechanical trauma caused by making the hole in the otic capsule.

The methods used in this study did not permit conclusive identification of the pigmented material that was found to accumulate in the stria and spiral prominence. The golden-brown pigment granules had the light-microscopic appearance of melanin. However, lipofuscin pigment has a similar color and granularity and it has been shown to occur in the tissues of the lateral cochlear wall in association with cellular degeneration (Takahashi, 1971). In view of the fact that the strial cells sustained considerable damage in our experimental material, it seems reasonable that at least a portion of the pigment was lipofuscin that accumulated as a result of intense lysosomal activity. On the other hand, it must be remembered that melanin pigment is also known to increase as a result of trauma. Melanocytes of the skin, for example, respond to injury in a variety of ways. They can increase in size, proliferate by mitosis, or increase their rate of melanin synthesis (Giacometti et al., 1972). In addition, these cells are chemotactic; that is, they can move about in response to chemical stimuli (Kitano and $\mathrm{Hu}, 1972$ ).

Unfortunately, definitive histochemical testing of the pigment found in our specimens was not possible because it would have rendered the tissue unsuitable for morphometric analysis. However, the results of the present study do indicate that the pigmented material was not simply osmium-stained lipid, since all specimens were bleached in hydrogen peroxide, which effectively removed reduced osmium from the tissue. Melanin would not have been affected by this procedure because higher concentrations of hydrogen peroxide and longer bleaching times are required for its decolorization (Lillie, 1965). Lipofuscin would also be expected to retain its brown color after brief exposure to hydrogen peroxide.

Other investigators have reported increased pigmentation of inner ear tissues in association with various types of trauma, including ototoxicity (Ruedi et al., 1953) and noise exposure (Shaddock et al., 1984). However, the pigment has never been definitively identified. The increase in pigment density observed in the present study was found in both sham-operated animals and in those with surgical rupture of Reissner's membrane. It therefore seems that trauma of the lateral wall structures (whether it be mechanical or toxic) is an essential factor in provoking the reaction. Further studies, utilizing histochemical, electron microscopic, and fluorescence techniques will be necessary to clarify this interesting phenomenon.

The conclusions of this study are most easily summarized by referring to Fig. 3. The importance of evaluating all of the vessels of the lateral wall is supported by the number of statistically significant effects seen in vessels other than the stria vascularis vessels. The importance of evaluating the vessels as three distinct systems is supported by the different reactions of these three systems to the variables measured; combining measurements of these variables across vessel systems would have significantly obscured the results.

\section{Acknowledgements}

The authors wish to thank Dr. William Ahroon for writing the software used in this project, and Mr. George Turrentine for technical assistance. This project was supported by National Institute of Occupational Safety and Health grant No, 1 RO1 OH1518-01 and U.S. Army Medical Research and Development Command grant No. DAMD 17-83-G-9555.

\section{References}

Albrecht, K.H., Gaehtgens, P., Pries, A. and Heuser, M. (1979): The Fahraeus effect in narrow capillaries. Microvasc. Res. $18,33-47$.

Cameron, R. (1967): Inflammation and repair. In: Pathology, 3rd Edn., Vol. 1, pp. 31-52. Editor: S.L. Robbins. W.B. Saunders, Philadelphia.

Duvall, A.J. (1968): Ultrastructure of the lateral cochlear wall following intermixing of fluids. Ann. Otol. 77, 317-331.

Duvall, A.J. and Hukee, M.J. (1981): Morphological aspects of stria dysfunction. In: Ménière's Disease. Pathogenesis, Diagnosis and Treatment, pp. 86-98. Editors: K.-H. Vosteen, H. Schuknecht, C.R. Pfaltz, I. Wersäl, R.S. Kimura, C. Morgenstern and S.K. Juhn. Thieme-Stratton, New York.

Duvall, A.J. and Rhodes, V.T. (1967): Ultrastructure of the organ of Corti following intermixing of fluids. Ann. Otol. $76,688-708$.

Eldredge, D.H., Covell, W.P. and Davis, H. (1957): Recovery from acoustic trauma in the guinea pig. Laryngoscope 67 , $66-84$. 
Folkow. B. and Neil. E., eds. (1971): The viscosity factor. In: Circulation, p. 29. Oxford University Press, Oxford.

Fulton, G.P. (1970): Structure and function of the microvascular system. In: Microcirculation, Perfusion and Transplantation of Organs. Academic Press, New York.

Fung. Y.C., Zweifach, B.W. and Intaglietta, M. (1965): Elastic environment of the capillary bed. Circ. Res. $19,441-461$.

Giacometti, L., Montagna, W. Bell, M. and Hu, F. (1972): Epidermal melanocyte proliferation in skin wound healing and after ultraviolet irradiation in rhesus monkey. In: Pigmentation: Its Genesis and Control, pp. 451-459. Editor: V. Riley. Appleton-Century-Crofts, New York.

Hawkins, J.E. Jr. (1971): The role of vascoconstriction in noise-induced hearing loss. Ann. Otol. 80. 903-914.

Kimura, R.S. (1962): Experimental blockage of the endolymphatic duct and sac and its effect on the inner ear of the guinea pig. Ann. Otol. 76, 664-687.

Kitano, Y. and Hu, F.: Morphological changes in melanocytes of the great bushbaby in vitro. In: Pigmentation: Its Genesis and Control, pp. 71-88. Editor: V. Riley. Appleton-Century-Crofts, New York.

Knisely, M.H., Eliot, T.S. and Block, E.H. (1945): Sludged blood in traumatic shock. Arch. Surg. 51, 220.

Lawrence, M. (1966): Histological evidence for localized radial flow of endolymph. Arch. Otolaryngol. 83, 406-412.

Lawrence, M. and McCabe, B.F. (1959): Inner-ear mechanics and deafness. J. Acoust. Soc. Am. 171, 1927-1932.

Lawrence, M. and Yantis, P.A. (1957): Individual differences in functional recovery and structural repair following overstimulation of the guinea pig ear. Ann. Otol. 66, 595-621.

Lawrence, M., Wolsk, D. and Litton, W.B. (1967): Circulation of the inner ear fluids. Ann. Otol. 76, 664-687.

Lillie. R.D. (1965): Histopathologic Technic and Practical Histochemistry, 3rd Edn. McGraw-Hill Book Co. New York.

Nakamura. F. (1973): Electrophysiological and cytochemical study of ototoxity of dihydrostreptomycin. Ann. Otol. Rhinol. Laryngol. 66, 1080-1112.
Rhodin. J.A.T. (1973): Electron microscopic observations on small blood vessels. In: Vascular Disorders and Hearing Defects, pp. 23-41. Editor: A.J, de Lorenzo. University Park Press, Baltimore.

Ruedi. L., Graf. K. and Tschirten, B. (1953): Vorläufige Mitteilung über die toxische Wirkung von Neomycin auf das Gehororgan des Meerschweinchens. Schweiz. Med. Wochenschr. 83,951.

Schuknecht, H.F. (1981): The pathophysiology of Ménière's disease. In: Ménière's Disease. Pathogenesis, Diagnosis and Treatment, pp. 10-15. Editors: K.-H. Vosteen, H. Schuknecht, C.P. Pfaltz, J. Wersäl, R.S. Kimura, C. Morgenstern and S.K. Juhn. Thieme-Stratton, New York.

Schuknecht. H.F. Benitez, J.T. and Beekhuis, J. (1962): Further observations on the pathology of Ménière's disease. Ann. Otol. 71. 1039-1053.

Shaddock, L.C., Hamernik, R.P. and Axelsson, A. (1984): Cochlear vascular and sensory cell changes induced by elevated temperature and noise. Am. J. Otolaryngol. 5. $99 \ldots 107$.

Shaddock, L.C. Hamernik, R.P. and Wright. C.G. (1985): A morphometric technique for analysis of cochlear vessels. Hearing Res. 20, 109-117.

Spoendlin. H. (1976): Anatomical changes following various noise exposures. In: Effects of Noise on Hearing. pp. 69-89. Editors: D. Henderson. R.P. Hamernick, D.S. Dosanjh and J.H. Mills. Raven Press. New York.

Takahashi. T. (1971): The ultrastructure of the pathologic stria vascularis and spiral prominence in man. Ann. Otol. Rhinol. Laryngol. 80, 721-735.

Voldrich, L. (1972): Experimental acoustic trauma. Part I. Acta. Otolaryngol. 74, 392-397.

Wells, R.E. (1965): Rheology of Blood in Low Flow States: in Shock and Hypotension. Grune and Stratton. New York.

Zar, J.H. (1980): Biostatistical Analysis, pp. 159-161. Prentice-Hall. New York.

Zweifach, B.W. (1971): E.M. Landis Award Acceptance Speech. Microvase. Res. 3, 345-353. 